doso en la 1

ar ejemplos a

is funcionalidac uso, dependiende encarnan los conceptos detr por e $\Lambda$ influ
$\mathrm{Pe}$ infin:

Las formas $d r$ oceso de sig ialidad .

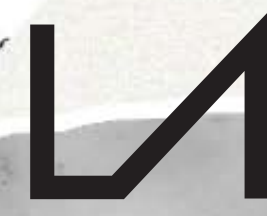

R E V I S A
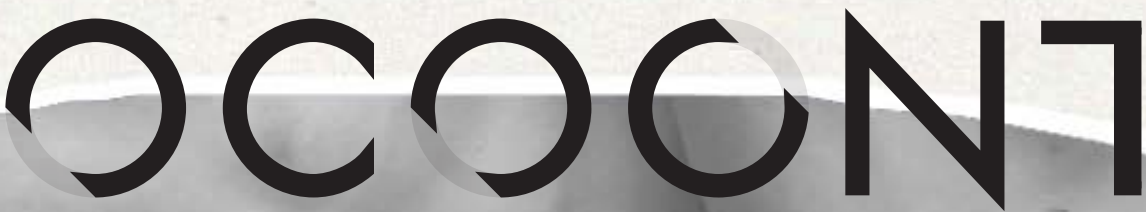

D $E$

No $6 \cdot 2019 \cdot$ ISSN 2386-8449

"El producto del diseñador es un proyecto, el estado previo de un objeto", Entrevista con Norberto Chaves, por Fernando Infante

El papel de la investigación y la teoría en diseño. Una conversación abierta, por Fernando Infante y María Jesús Godoy

UT PICTURA POESIS

Abandonar la escritura. Poesía experimental y manifiesta, Ignacio Gómez de Liaño

PANORAMA: FILOSOFÍA DEL DISEÑO Sección coordinada por Fernando Infante y María Jesús Godoy

Pensar el diseño, Fernando Infante y María Jesús Godoy (Coordinadores)

TEXTOS INVITADOS

Estatus y estado del điseño más allá del objeto, Pedro Medina Reinón

Mar de Nubes, Cuerpo de Cristal, Dionisio González

ARTÍCULOS

Understanding Design Aesthetics beyond Functional Beauty accounts, Lucía Jiménez Sánchez

Estética y diseño industrial: debates y controversias, Joan M. Marín

Del ornamento al delito. El diseño y la sociedad en Charles Baudelaire y Adolf Loos, Jorge López Lloret

When is Architecture not Design? Saul Fisher

Diseño y habitabilidad: una aproximación basada en los lenguajes de patrones, Antonio Hidalgo Pérez

Marcel Breuer: un diseñador global. Experiencias en el ámbito de la vivienda prefabricada, Salvador J. Sanchis, Ignacio Peris y Pedro Ponce Diseño y artes escénicas: el papel de Oskar Schlemmer en Das Triadische Ballett y la actualidad de la Bauhaus, Milagros García Vázquez Lo performativo en prácticas de arte y diseño actuales vinculadas a procesos de innovación social. El caso de La Venezia che non si vede y de La borda, Tània Costa Gomez

Articulaciones de la estética y el diseño. El caso de la evaluación a partir de la investigación dirigida en la carrera de diseño escénico de la Universidad de las Artes de Cuba, Mara Rodríguez Venegas y Xiomara Romero Rojas

SUPLEMENTO

El diseño, la ciudad y un lápiz de labios, Mercedes Espiau, Mar García Ranedo y Alejandro Rojas mas. 


\section{UつCつCNTE}

No $6 \cdot 2019 \cdot \operatorname{ISSN} 2386-8449 \cdot$ DOI 10.7203/LAOCOONTE.5.15381

https://ojs.uv.es/index.php/LAOCOONTE/index

COORDINACIÓN EDITORIAL

Anacleto Ferrer (Universitat de València)

Francesc Jesús Hernàndez i Dobon (Universitat de València)

Fernando Infante del Rosal (Universidad de Sevilla)

SECRETARÍA DE REDACCIÓN

Lurdes Valls Crespo (Universitat de València)

Vanessa Vidal Mayor (Universitat de València)

COMITÉ DE REDACCIÓN

Tamara Djermanović (Universitat Pompeu Fabra), Rosa Fernández Gómez (Universidad de Málaga), Anacleto Ferrer (Universitat de València), Ilia Galán (Universidad Carlos III), Ana María García Varas (Universidad de Zaragoza), María Jesús Godoy (Universidad de Sevilla), Fernando Infante del Rosal (Universidad de Sevilla), Miguel Ángel Rivero (Universidad de Sevilla), Miguel Salmerón (Universidad Autónoma de Madrid), Gerard Vilar (Universitat Autònoma de Barcelona).

COMITÉ CIENTÍFICO INTERNACIONAL

Rafael Argullol* (Universitat Pompeu Fabra), Luis Camnitzer (State University of New York), José Bragança de Miranda (Universidade Nova de Lisboa), Bruno Corà (Università di Cassino), Román de la Calle* (Universitat de València), Eberhard Geisler (Johannes Gutenberg-Universität Mainz), José Jiménez* (Universidad Autónoma de Madrid), Jacinto Lageira (Université Paris 1 Panthéon-Sorbonne), Bernard Marcadé (École Nationale Supérieure d'Arts de Paris-Cergy), Elena Oliveras (Universidad de Buenos Aires y Universidad del Salvador), Pablo Oyarzun (Universidad de Chile), Francisca Pérez Carreño* (Universidad de Murcia), Bernardo Pinto de Almeida (Faculdade de Belas Artes da Universidade do Porto), Luigi Russo (Università di Palermo), Georges Sebbag (Doctor en Filosofía e historiador del surrealismo), Zoltán Somhegyi (University of Sharjah, United Arab Emirates), Robert Wilkinson (Open University-Scotland), Martín Zubiria (Universidad Nacional de Cuyo). *Miembros de la Sociedad Española de Estética y Teoría de las Artes, SEyTA

\begin{tabular}{lll}
\hline DIRECCIÓN DE ARTE & REVISIÓN DE TEXTOS & TRANSCRIPCIÓN DE TEXTOS \\
El golpe. Cultura del entorno & Antonio Cuesta & Álvaro G. Serna
\end{tabular}

(cc) BY Excepto que se establezca de otra forma, el contenido de esta revista cuenta con una licencia Creative Commons Atribución 3.0 España, que puede consultarse en http://creativecommons.org/licenses/by/3.0/es/deed.es

EDITA

\section{SEyTA.}

CON LA COLABORACIÓN DE

\begin{tabular}{|c|c|c|c|}
\hline $\begin{array}{l}\text { VNIVERSITAT } \\
\text { ID VALENCIA } \\
\text { Institut a Creativitat } \\
\text { i|nnovacions Educatives }\end{array}$ & $\begin{array}{l}\text { VNIVERSITAT } \\
\text { IE ÖVALENCIA Departament de Filosofia }\end{array}$ & 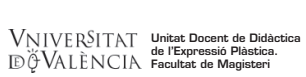 & \\
\hline $\begin{array}{l}\text { DEPARTAMENTO DE ESTÉTICA } \\
\text { E HISTORIA DE LA FILOSOFIA }\end{array}$ & $\frac{\text { UAW }}{\frac{\text { UNIVERSIDAD AUTONOMA }}{\text { DE MADRID }}}$ & $\begin{array}{l}\text { AB } \\
\text { Universitat Autònoma } \\
\text { de Barcelona }\end{array}$ & 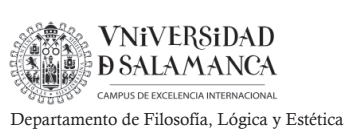 \\
\hline
\end{tabular}

LAOCOONTE aparece en los catálogos: 


\section{LつCつCN7E}

"Cuanto más penetramos en una obra de arte más pensamientos suscita ella en nosotros, y cuantos más pensamientos suscite tanto más debemos creer que estamos penetrando en ella".

G. E. Lessing, Laocoonte o los límites entre la pintura y la poesía, 1766.

Vo hay cól.

létodo, de pen.

:ión en general. Ith

zar la forma para el $\mathrm{n}$.

eptual por las orígenes

la, el objeto, la exposición

storia, porque existe en el $\mathrm{m}$

das sus raíces. Desde alli cc _. panoram

n conceptual y donde el émencia del con 'iseñado, como es el a al objeto y el di $\begin{array}{ll}\text { igen } \mathrm{de}^{\text {to }} \text { la inmer } & \text { tolvidada, o comc } \\ \text { trozo de madera ar }\end{array}$ a manera dorm comunicar ene nundo. Seguin? sngo en manos te el método $C$ les. A partir c teria prima $\mathrm{p}_{\mathbf{c}}$

'xto se puede:

¿ño, en proyea

amientos de $\mathrm{u}$

a conscie-

.)

en la publicación jue "plos de la impor te las nalidades porqu ura un ${ }^{2}$ diendo de qui zenerar $\mathrm{u}$ ción de nr? lne

in-

n-

is.

le http:,

le crear visualidades. A partir de.

ellas la propia materia prima para un en que desde un texto se puede generar $u_{11}$ i

Pensar en diseño, en proyección de nue

posibles comportamientos de una colecti

presente como una consciencia del hecho que estamos elaborando, significac

nuestro entorno (..)

Cardoso, R. C. Rafael. (2014). Design para um mundo complexo. Sãc asil: Cosac Naify. 


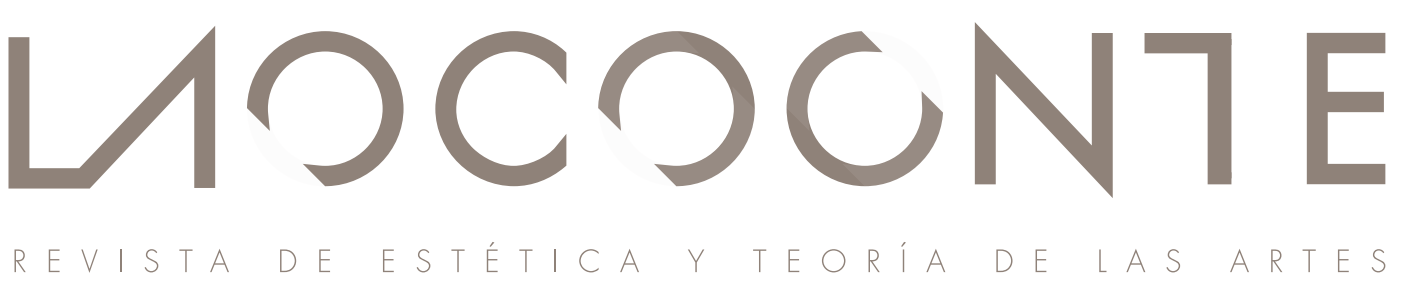

$\mathrm{N}^{\circ} 6 \cdot 2019$

PRESENTACIÓN

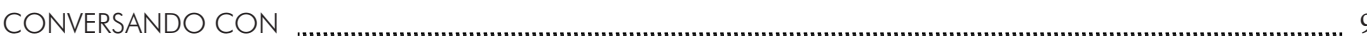

"El producto del diseñador es un proyecto, el estado previo de un objeto", Entrevista con Norberto Chaves,

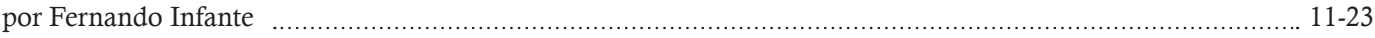

El papel de la investigación y la teoría en diseño. Una conversación abierta, por Fernando Infante

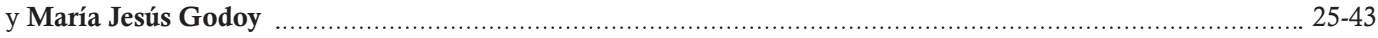

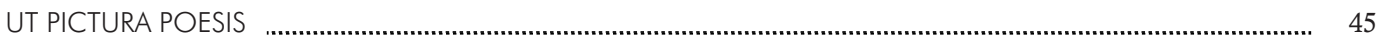

Abandonar la escritura. Poesía experimental y manifiesta, Ignacio Gómez de Liaño ................................................ 47-95

Imágenes de Laocoonte n. 6, de Isadora Gonzaga ................................................................................................... 96-97

PANORAMA

FILOSOFÍA DEL DISEÑO

Pensar el diseño, Fernando Infante y María Jesús Godoy (Coordinadores) .............................................. 101-105

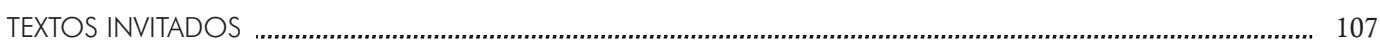

Estatus y estado del diseño más allá del objeto, Pedro Medina Reinón . ................................................... 109-125

Mar de Nubes. Cuerpo de Cristal, Dionisio González .............................................................................. 127-133

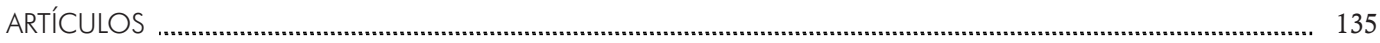

Understanding Design Aesthetics beyond Functional Beauty accounts, Lucía Jiménez Sánchez ................. 137-149

Estética y diseño industrial: debates y controversias, Joan M. Marín _...................................................... 150-164

Del ornamento al delito. El diseño y la sociedad en Charles Baudelaire y Adolf Loos, Jorge López Lloret ... $165-182$

When is Architecture not Design? Saul Fisher ……............................................................................. 183-198

Diseño y habitabilidad: una aproximación basada en los lenguajes de patrones, Antonio Hidalgo Pérez ...... 199-215

Marcel Breuer: un diseñador global. Experiencias en el ámbito de la vivienda prefabricada,

Salvador José Sanchis, Ignacio Peris y Pedro Ponce

Diseño y artes escénicas: el papel de Oskar Schlemmer en Das Triadische Ballett y la actualidad de la Bauhaus, Milagros García Vázquez

Lo performativo en prácticas de arte y diseño actuales vinculadas a procesos de innovación social.

El caso de La Venezia che non si vede y de La borda, Tània Costa Gomez

Articulaciones de la estética y el diseño. El caso de la evaluación a partir de la investigación dirigida en la carrera de diseño escénico de la Universidad de las Artes de Cuba, Mara Rodríguez Venegas

y Xiomara Romero Rojas

SUPLEMENTO 
Walter Gropius. La vida del fundador de la Bauhaus, Jorge Martínez Alcaide

¿Qué significa pensar la política desde la estética? Àger Pérez Casanovas

Ideologías estéticas en los orígenes de la pintura moderna, José Luis Plaza Chillón 300-303

Sobre a estética, Luis Carlos Pereira

Músicas populares. Sociedad y territorio: Sinergias entre investigación y docencia, Mar Aleixandre Badenes.

307-309

La necesidad de la mirada antropológica sobre la literatura, Pablo de Benito David

A propósito de Chandler, o la novela policíaca como tratado filosófico, Juan Evaristo Valls Boix

Videre aude!, Anacleto Ferrer

La inaplazable memoria del dolor y el sufrimiento, Antonio Notario Ruiz

La alargada sombra de la pintura, Raquel Baixauli

Sondear la maravilla, Juan Evaristo Valls Boix

... Y lo sabes, Marc Hernández Montoro

Arqueologías de la modernidad en las artes. Ensayo estético, Carlota Fernández-Jáuregui Rojas

Estética de la Instalación, Luis Cemillán Casis

La Herencia de otra época, María Jesús Godoy Domínguez

Del Theatrum Mundi al Gran Vidrio, Miguel Salmerón Infante

Imágenes de Isadora Gonzaga.

Fotografía de portada de Tamara Djermanovic intervenida por Isadora Gonzaga.

Los coordinadores de la sección Panorama: Filosofia del diseño agradecen

a Antonio Molina Flores su colaboración. 
ner.

llobj vidada, o de ma la publica. los de la im nalidades po ndientn $\mathrm{A}$ -
, la

que e.

usdño, si nn

ज. " da yara el mu tual y d

or enc or las orígenes un tmo, fía del diseño,

rpintero que'curra la forma de

eña Desige para un mundo complexo, de los bienes producidos por el hombre :tores subjetivos también influyen en su

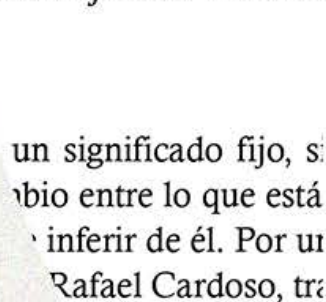

Rafael Cardoso, tri

No hay cómo no e método, de pensa 1, donde la reación en geperal. salizar la forma pa. rue amb ${ }_{\text {Snceptual por }}{ }^{1}$

$$
\text { -rola ol } n^{\prime}
$$

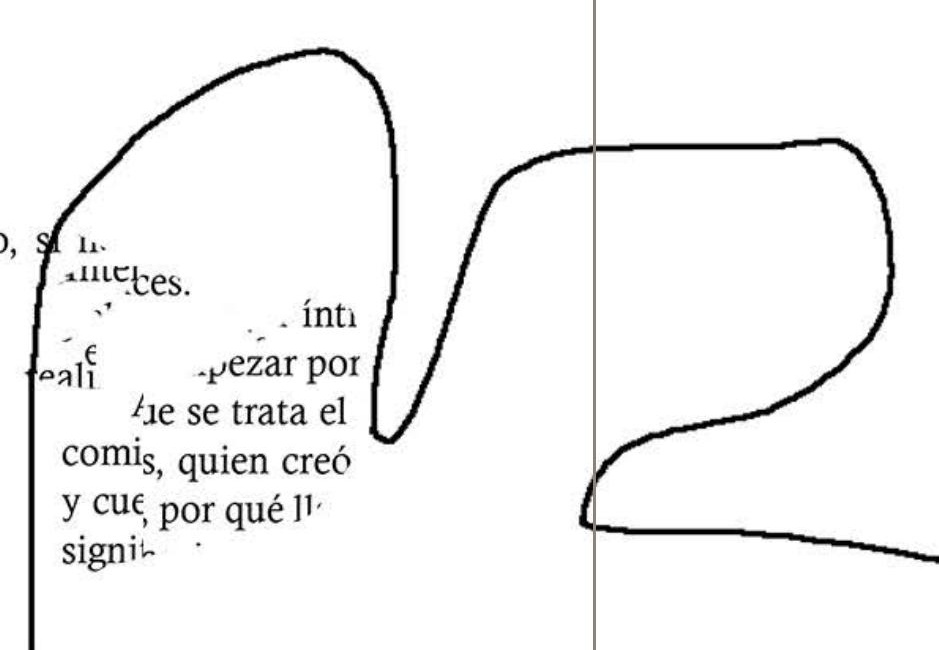

LOCOCNTE

PANORAMA: FILOSOFÍA DEL DISEÑO

Fernando Infante del Rosal y María Jesús Godoy Domínguez

(Coordinadores) 
¿s raír

„ue exir' e es, qui

a concrablot

i ser dica'oniunte

sol

has un us

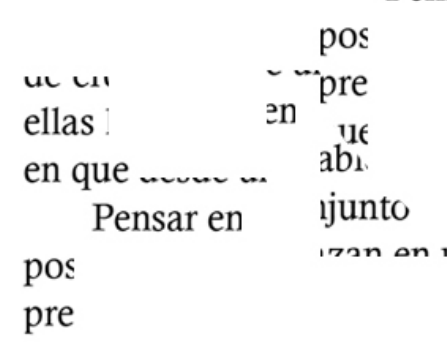

tus

art

ma
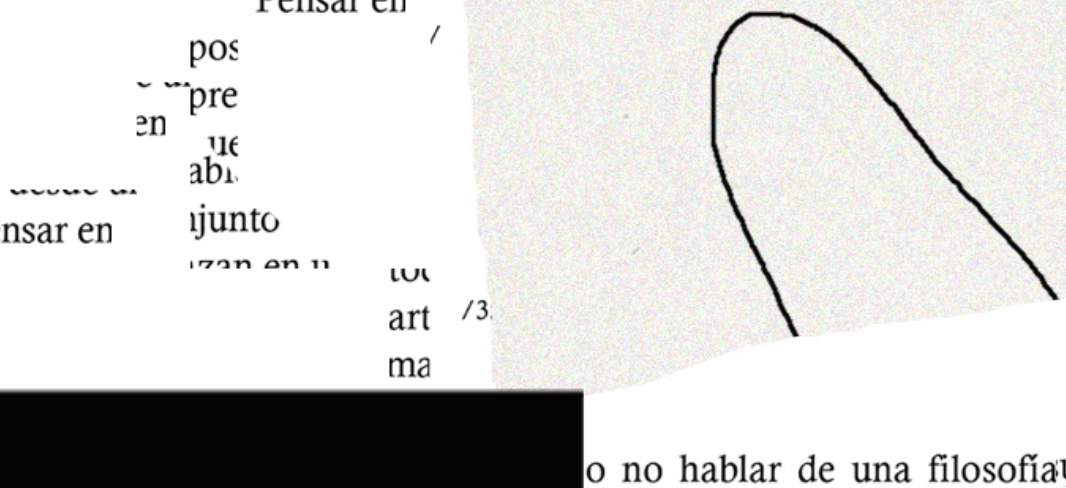

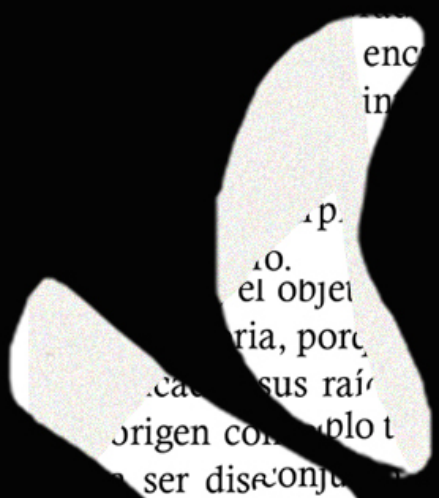

ser disfionj

seventrelazar

Pensa

nfinitame

contrar su.

hacex conscien

de las mas de

hago

?cié

lo que

presente

ralidades.

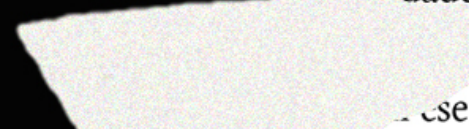

$\rightarrow$ ras que $c$

nenge, para
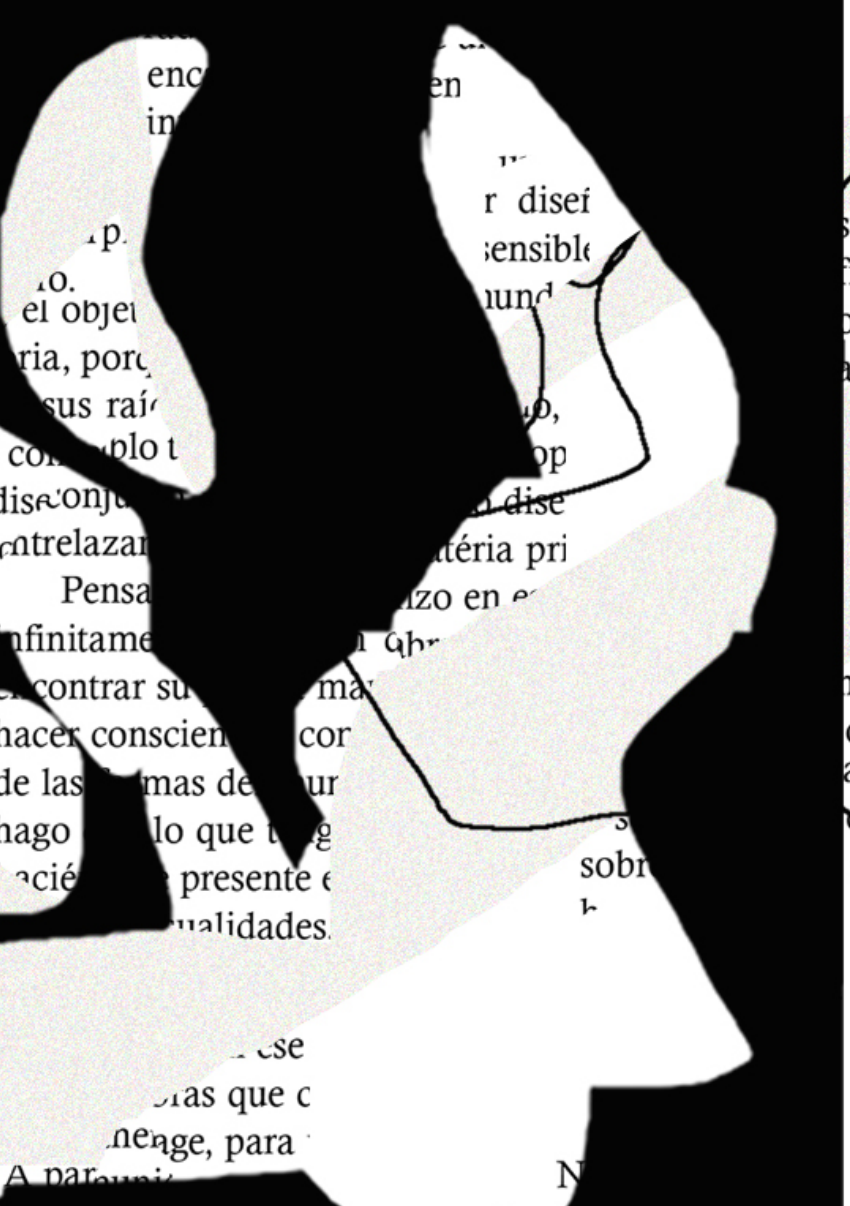

nov

o no hablar de una filosofiav

$\mathrm{Cr}$ Intentaré exponer

rea. el mundo :-

concenes

novg'

su histc.

incadas $s$ '

prigen

a.

ungiv,

do sensibleíaa

o el hilo den carp.

al y urn Curfo.

semo es el panor ma 1

intyanencia del doncep

objeto y el diseñado.

como un carplo

'sa amorfo.

$\eta$ brasileñ ${ }_{\text {no }}$ tier ${ }^{\text {to }}$,

tancia de $e_{\text {el int }}{ }^{\text {irtir de }}$.

No hay cómolos factienc .ma para $\mathrm{u}$ de método, de penso use: $c^{2}$ puede gene creación en general. 1.

en proyección realizar la forma para $\epsilon_{\text {tier }}$ conceptual por las orígs entos de una novela, el objeto, la exr su historia, porque exir.

"cadas sus raír

, en pro para um 1

ientos fincadas sus

origen 
-.iuso.

er el diseño y ?

.tgen de nuestro $\mathrm{m}$

spia manera de constr

nte y comunicar el pro

/351/

lel diseño, si no hablr

in formon. of 1

nror en dir.. o.

hace s

descifra ᄂ.

vos is snli,

351/

'To hay cómo

'n de ne
UOCOCNTE

PANORAMA: FILOSOFÍA DEL DISEÑO

TEXTOS INVITADOS

\section{in}

rar 1

de

col

hech ae metuuu, -

creación en ger

realizar la form

conceptual por

novela, el objet

su historia, por

fincadas sus ra

origen concept

a ser diseñado.

sobrevolando 1

hace surgir la $\mathrm{f}$

descifra una ler

y se la aplica a 
¿s raír

$$
\text { yue exirs a es, qui }
$$

a concrablot . Sor dica'oniunte

sol

has un us

un un

ellas

en que

Pensar en pos

ellas: $\quad$ en pre

en que

Pensar en

pos

pre

il tus

art

ma

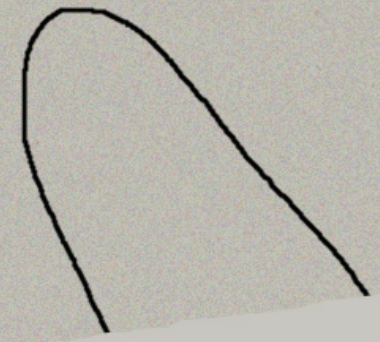

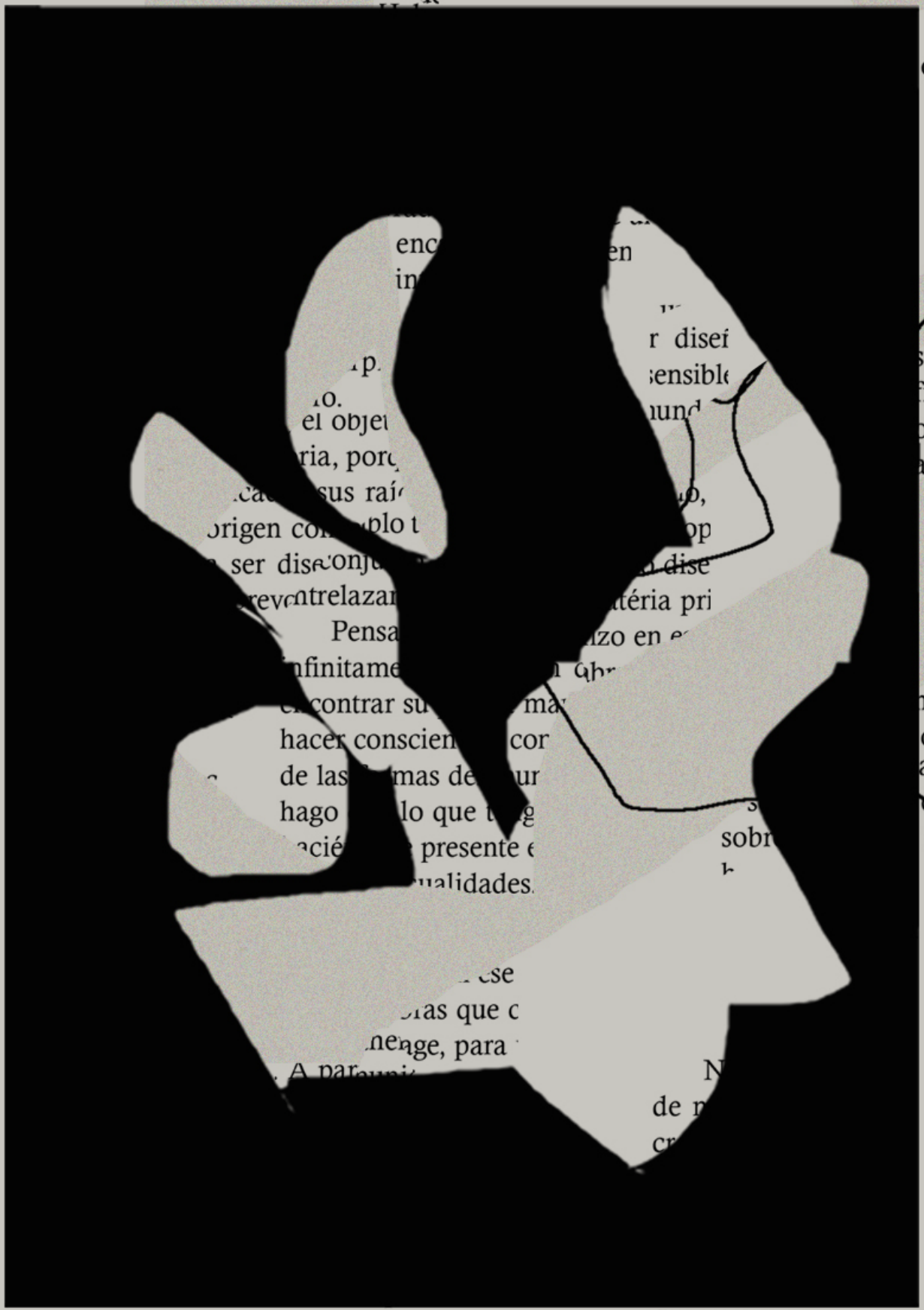

, en pro para um 1

ientos fincadas sus

origen

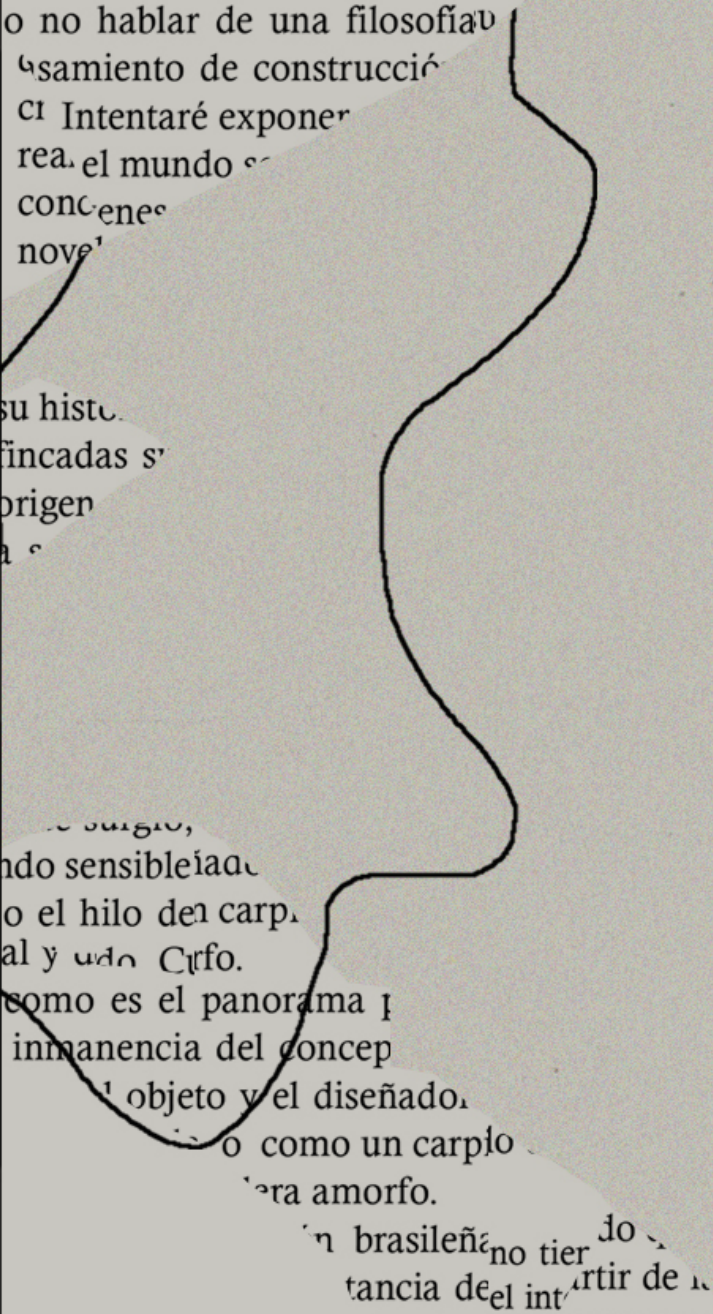

No hay cómolos factienc -ma para $u$ de método, de penso use: $\mathrm{c}^{2}$ puede gene creación en general. 1. en proyección realizar la forma para $\epsilon_{\text {tier }}$ conceptual por las oríg $\epsilon^{-}$ novela, el objeto, la exr $\mathrm{F}_{\mathrm{e}}$, su historia, porque exir

" ncadas sus raír

v concrablo también de fael. (2014). a'onjunto con la for

1azan en un comná 


\title{
Mar de Nubes. Cuerpo de Cristal
}

\author{
Sea of Clouds. Body of Glass
}

\author{
Dionisio González*
}

\section{Resumen}

E1 movimiento moderno en arquitectura descubre, desde los primeros estudios en la Bauhaus, la membrana de cristal como un logro del diseño que interpela al exterior. La vivienda así tiene la virtud del abrigo y el espesor climatérico; es decir, la integración del mundo como interventor del espacio. En esa carrera hacia la transparencia el modelo miesiano de la abstracción, el equilibrio y la reducción de las formas se multiplicó, se replicó sin la sensibilidad de éste hacia los materiales. Pero ese ser replicante que se viraliza como modelo de éxito fue generando una amorfia constructiva mimetizada por soluciones complotadas con los órganos de poder y la revolución digital. El mundo es ya pura membrana, pantalla, ventana e interfaz desde donde penetrar a espacios que, pese a su insubsistencia y su trasparencia, bien podrían "concret/ar" una bunkerización del cristal dada la pasividad y la aquiescencia del sujeto ante la pérdida definitiva de espesor.

Palabras clave: Bauhaus, expresionismo, diseño, utopía, cristal, arquitectura, ventana de Overton.

Entre un mar de nubes, destacan pilares y arcos de cristal verde esmeralda por encima de la cumbre nevada de una alta montaña. Arquitectura del armazón, del espacio abierto al universo. Arquitectura y casa no son conceptos inseparables.

\section{Bruno Taut, Arquitectura Alpina (1997: 1)}

Por lo general, vivimos en espacios cerrados. Éstos forman el medio en el cual se desarrolla nuestra cultura. Nuestra cultura es, en gran medida, el producto de nuestra arquitectura. Si queremos elevar nuestra cultura a un nivel superior, para bien o para mal, estaremos obligados a transformar nuestra arquitectura, y esto sólo nos será posible si a los espacios que habitamos les sustraemos su carácter cerrado. Esto podemos lograrlo con la introducción de la arquitectura de cristal, que deja que la luz del sol, la luz de la luna y de las estrellas no se filtre sólo a través de un par de ventanas, sino que entre directamente a través del mayor número posible de paredes que sean por entero de cristal, de cristal policromado. El nuevo entorno que habremos creado de esta forma nos tiene que traer una nueva cultura.

Paul Scheerbart, La arquitectura de cristal (1998: 2)

Paul Scheerbart escribió La arquitectura de cristal en 1914, libro dedicado a Bruno Taut. En esa suma de aforismos, que pergeña una sociedad atravesada por la luz que

* www.dionisiogonzalez.es dionisiogz@gmail.com 
permiten las grandes estructuras paredañas de cristal, se encerraba el deseo inaplazable del pacifismo. Un entramado soteriológico de efectos continuados de iluminación como único emplazamiento para la salvación. De hecho, para Scheerbart, la arquitectura de cristal convertiría las habitaciones humanas en catedrales y, por tanto, sus efectos se esparcirían como el silencio sobre las estancias y sus dueños. Bruno Taut, por su parte, construyó en 1914, en Colonia, con motivo de la exposición del Werkbund, el "Pabellón para la Industria del Vidrio y del Cristal" y algunos de los versos de Scheerbart fueron inscriptos sobre las paredes del poliedro de base (1998: 67).

Lo paradójico es que el escritor utópico, pese a sus críticas a la objetivad, anticipará la nueva construcción edilicia de integumentos de cristal envolvente y permeable del objetivismo europeo de los años 30 en arquitectura. Mientras el expresionista Taut, por su lado, con su manifiesto de "Arquitectura Alpina" publicado en 1919 aspiraría a cristalizar la montaña como un efecto tamizador del orden natural para la evitación de la guerra. Guerra que para Taut tiene su origen en la desocupación y el aburrimiento, como así expresara en la carta destinada a Guillermo II, Emperador de Alemania y Rey de Prusia. Lo cierto es que, al igual que Paul Scheerbart, Taut parece significarse en décadas posteriores como un defensor de una arquitectura de fruncimientos urbanos y paisajísticos que, a su vez, proclama una construcción de estructuras públicas no indispensables.

En esa actuación utópica sobre los Alpes, Taut predeterminaba la arquitectura como acción cósmica. La naturaleza como construcción, como fuerza e idea, como pura formalidad y curvidad que se trastoca mundo edificado. Por entonces, ya había una cierta tendencia a encapsular el jardín con bellas cúpulas de cristal para su cumplimiento botánico y Ebenezer Howard había publicado, en 1902, su manifiesto sobre "Las Ciudades Jardín del Mañana" donde sociedad humana y belleza natural debían disfrutarse conjuntamente, es decir; frente a la dicotomía campo-ciudad aparece una nueva sociedad que habita un territorio de mediaciones cuyos habitantes son íncolas de un espacio intermedio, no marginal, ni tangente sino plenamente conclusivo.

Se sabe que las teorías de Scheerbart estuvieron presentes en la construcción de los primeros manifiestos de la Bauhaus, pese a que la concepción expresionista de la arquitectura ideada por el poeta presentaba formas orgánicas cristalográficas, y "la modernidad triunfante se manifestaría en todo su esplendor a través de la planeidad, obtenida por el procesado industrial de la sílice (el flotado) y su geometría rectangular bidimensional" (Taut, 1997: 15). Aun así, la Bauhaus buscaba igualmente una nueva arquitectura que excediera el campo de la construcción. Walter Gropius indicaba, en 1935, que "como consecuencia directa de la creciente predominancia de los vacíos sobre las superficies opacas, el cristal adquiere una importancia estructural desconocida hasta hoy. Su brillo etéreo y el hecho de que parezca flotar entre pared y pared, ingrávido como el aire, da una nota alegre a las viviendas modernas" (Gropius 1966: 28).

Aunque a finales de 1923 Gropius había iniciado su alejamiento del expresionismo (incluso antes de la llegada de Moholy-Nagy principal valedor docente de los ideales constructivistas), hay algo más que lo vincula a Scheerbart y Taut: la conciencia del punto elevado y la impresión de que las ciudades ya nunca más serán penetrales, oscuras, ciegas, discontinuas. Por el contrario, serán luminosas, esclarecedoras, ya que desde el cielo el descifre de su exterioridad, de su revestimiento, dará una nueva comprensión a la totalidad del tejido urbano. La vista aérea, para Taut, modificará radicalmente la arquitectura, ésta tendrá una función redentora, anagógica. Para Gropius, la 
vista en alza mostrará la arquitectura como un sistema de émbolos donde las cubiertas se interpolan como una masa verde y especiosa. "Desde el cielo los tejados verdes de las ciudades del futuro parecerán una sarta interminable de jardines colgantes" (Gropius, 1966: 31).

En realidad, este es el sueño largamente explorado en el que los jardines domestican la naturaleza para un uso recreativo al igual que los parques introducen la naturaleza en las grandes ciudades. Es el sueño de intervenir lo natural como masa practicable donde hitar límites a un territorio ilimitado. El acotamiento del espacio variable y natural desde la arquitectura es como la encuadernación de un manifiesto de contenidos de contigüidad. Racionalizar el acontecimiento y lo contingente es, por otra parte, una audacia sin precedentes. Este reto de acristalar la práctica de lo concurrido y lo eventual forma parte de la experiencia del mundo tras la membrana. Es el efecto que transfiere el hábito de la visión sin el accidente de lo atmosférico.

Henri Lefebvre nos indica cómo Frank LLoyd Wright en la primera década del siglo XX "comenzó a suprimir el muro que sellaba un espacio y separaba el dentro del afuera, el interior del exterior. El muro se redujo a una superficie y ésta, a su vez, a una membrana transparente. La luz entraba a raudales en la casa; y en cada "pieza" de la misma podía contemplarse la naturaleza. Desde ese momento, la materialidad del volumen y del peso del muro dejó de jugar un rol primordial en la arquitectura. La materia ya no sería sino una envoltura del espacio, cediendo el predominio a la luz que poblaba ese espacio. Siguiendo la tendencia de la filosofía, del arte y de la literatura, de la sociedad entera hacia la abstracción, la visualización y la espacialidad formal, la arquitectura trató de alcanzar la inmaterialidad" (Lefebvre 2013: 339).

Sigfried Ebeling había escrito, en 1926, "Der Raum als Membram". El espacio como membrana y dos años antes, en el periódico Junge Menschen de la Bauhaus en Weimar, publicó el artículo "Células Espaciales Cosmológicas". Se sabe que Mies Van der Rohe tenía dicho libro lleno de anotaciones. Había una corriente de interpretación que, apoyada en el perfeccionamiento técnico del acero y el hormigón que reducía el área de ocupación de los elementos de carga, buscaba la suspensión etérea apoyada por cristaleras continuas divididas por finos montantes de acero. La arquitectura como cosmovisión, lo que Sloterdijk define como espumidificación del mundo que en realidad, pese a los sueños monoesféricos de la modernidad que perseguían un hiperglobo integrador, termina siendo en nuestra contemporaneidad una membrana de membranas que desde su centro, que ocupa todos los centros, manda mensajes que el remitente acusa en un laberinto de misivas (Sloterdijk 2003: 73).

Si rescatamos este deseo de inmaterialidad de la arquitectura es fácil entender como nuestras grandes urbes se han ido conformando esbeltas y acristaladas, de tal forma que el cielo quede contenido en altos prismas simplificados y neutros, que cuando irrumpe la noche brillan en intervalos como infinitas luciérnagas. En cierto modo, la Bauhaus, que promovía una fórmula de vivir conforme a un equilibrio entre el utilitarismo, la estética y la psicología, percibía como una nueva era maquinista arrollaba aquella comunidad antigua caracterizada por las artesanías, de tal manera que observaba una limitación del crecimiento democrático en aquellas grandes ciudades cuyas administraciones se fueron despersonalizando.

Gropius advertía, en 1956, cómo "arte ciencia y religión constituyen islas sin conexión entre sí; una nueva síntesis debe volver a hacer una totalidad de lo que ahora está, desgraciadamente, desintegrado" (Gropius 1959: 151). En efecto, parece que el 
trayecto temporal, ya siendo profesor en Harvard, hace a Walter Gropius plantearse cómo el sujeto de la gran ciudad está obligado a someterse a un poder distante. De algún modo, advierte cómo aquellos valores de transparencia que perseguía se vuelven indóciles; se vuelven, en definitiva, autónomos en su mímesis y expansión haciendo que aquello que fue hipotético y crítico se manifieste rizomático y literal. Gropius, que siempre alentó una arquitectura integral, una composición elemental de códigos de escala, espacio, forma y color -que vinculasen a los hombres más fuertemente que las palabras-, trataba de encontrar una terminología precisa a las ilusiones ópticas y su influencia psicológica.

Entre los efectos que buscaba discernir se encuentran el vértigo provocado por la altura y la transparencia y la agorafobia provocada por los espacios amplios, vacíos o abiertos. A este respecto, escribía, que las personas en el momento de cruzar un gran parque "se sienten perdidas en un espacio cuyo tamaño no está de acuerdo con la escala humana. Pero si se levantaran en ese espacio abierto algunos planos verticales tales como arbustos, cercos o paredes, dispuestos a la manera de las bambalinas de un teatro, la ilusión de seguridad se restablecería y desaparecería el temor, pues los ojos a tientas en ese espacio hallan ahora un sistema de referencia que les brinda apoyo; cuando encuentran un sólido en el campo visual, registran su contorno tal como lo hace el radar" (Gropius 1959: 45).

Aunque no le falta base científica, este pensamiento sorprende en la medida que alegoriza con cercos y paredes. Sin duda, existe el fundamento fuertemente arraigado en la arquitectura moderna de estilo Bauhaus, de estilo Internacional y de estilo Funcional de operar siempre sobre el vacío, de intervenir el espacio no mediado, de racionalizar la exuberancia o la explanación, sean éstos selva o desierto. La efemeralización que define desde el desarrollo tecnológico el hacer lo máximo con lo mínimo y que acuñara Buckminster Fuller llega a su máxima referencialidad con la cúpula geodésica de la Union Tank Car Company que éste construyera en Baton Rouge en Luisiana, en 1958, derruida en 2007, y que encerraba una superficie de más de 10.000 metros cuadrados. O sin duda la cúpula ballardiana propuesta como envoltorio sobre Manhattan. Estas estructuras ya se presagiaban en los jardines y parques de Joseph Paxton, en sus cármenes, invernaderos y pabellones de exposición. El gran Conservatorio de Chansworth construido en madera y vidrio en 1841 y demolido en 1920, fue entonces el mayor y más espectacular invernadero de Europa. Como lo fue más adelante el fascinante edificio, con su gran cúpula, Horticultural Building de Chicago diseñado por William Le Baron Jenney para la Exposición Universal de 1893.

Kevin Lynch cuando nos habla de obsolescencia planificada en edificios nos indica cómo la vida de éstos puede ser programada para una decadencia administrada. Lo ideal es que la previsión de vida de un edificio iguale su probabilidad de uso, pero esto casi nunca se produce. Podemos, dice, "planificar los usos intermedios y los accesos para sacar partido a los espacios vacíos temporalmente que facilitan los derribos" (Lynch 2005: 182). Es decir, que podemos especular con el vacío, con lo disfuncional, aplicándoles nuevos usos que aplazan o eliminan su declividad. Porque, finalmente, lo vacío es espacio para la libertad, más cuando es tangente con un régimen edilicio que contempla lo pleno o lo lleno como articulación urbana.

La arquitectura no formó parte del plan de estudios de la Bauhaus hasta 1927, aunque desde sus inicios en Weimar, en 1919, Gropius había hecho del edificio en su completud (der Bau) el propósito docente final. Mies Van der Rohe asumió la dirección 
de la Bauhaus en septiembre de 1930. Parece ser que Gropius ya se lo había ofrecido en 1928, casi al mismo tiempo del nombramiento de Hans Meyer que trajo, entre otros profesores, a Ludwig Hilberseimer para supervisar los proyectos de vivienda colectiva y urbanismo. Pero, la accidentada vida en Dessau, su traslado a Berlín, la célebre carta de la Gestapo que consiguió Mies, tras tres meses de negociaciones, y el final de esta escuela en 1934 provocarán un viaje diaspórico de sus profesores que seguirán impartiendo el espíritu de la Bauhaus desde el exilio. Mies y Hilberseimer continuaron su labor docente en Chicago, donde también lo hicieron Lászlo Moholy-Nagy, Hin Briedendieck, Walter Peterhans y Gyorgy Kepes.

Ludwig Hilberseimer, más proyectista que emprendedor, a diferencia de Mies, estaba gestando su proyecto The New City destinada a transformar integralmente vidas y territorios, pensando un sistema escalar que partía de la unidad mínima de la casa y se extendía hasta la inmensidad del paisaje en un ejercicio de absoluta coherencia y racionalidad (González Martínez 2015: 29). Es decir, seguía, de forma inercial, entablando diálogos teóricos entre el mundo natural y la actividad residencial. Este proyecto, que para algunos hubiera cerrado el movimiento moderno que Jürgen Habermas entendía inacabado, no era un postulado utópico, sencillamente su modestia no casaba con el optimismo constructivo de Estados Unidos, ni encajaba su idea de colonizar el territorio desde una especie de zonificación familiar en un momento de creciente verticalización concentracional y euforia por un modelo estratificado y erguido de edificación. Más interesantes parecían para ese momento, 1944, de renovación urbana, sus anteriores ideas sobre la ciudad-rascacielos de reificación pedestre, con pasarelas aéreas, calles bajas de tráfico rodado y túneles de metro superpuestos para la ciudad congestionada de Chicago. Lo cierto es que Hilberseimer, para la larga ideación de su proyecto que se prolongó durante 17 años, se apoyó en la obra de Bruno Taut y, concretamente, en su Die Stadtkrone (La corona de la ciudad).

Hilberseimer requería ciudades en curso de renovación urbana, un planeamiento desacotado. Una realidad descercada que se extendiera como una continuación del paseo y recurriese a la naturaleza en cuanto a posibilidad de expansión. Es decir, su New City se alejaría del centro para ubicarse en la inconclusión del paisaje y la periferia. Necesitaba el espacio franco donde elegir una estructura de recorrido unitario.

Pero el curso de los acontecimientos, en una sociedad de capital incremental, polarizaciones sociales y una creciente complejidad cultural, estaba más cerca de interpelar y fungir en el territorio urbano con los primeros bloques de apartamentos construidos con armazón de acero en el mundo en los números 860-880 de Lake Shore Drive (1948-1951) en Chicago. Diseñados por Mies van der Rohe junto al ingeniero Frank Kornacker. Se levantaron las 26 plantas ignorando cuánto se balancearían las estructuras. En esa misma época, Mies comenzaría a proyectar la Casa Farnsworth (1945-50), en Plano Illinois. Una segunda vivienda residencial, de una planta, sobre la llanura aluvial del río Fox. Abierta y cristalina sobre unos menudos zancos, inauguraba el efecto de transparencia. Efecto que, en 1951, le llevó a una demanda interpuesta contra Edith Farnsworth y una posterior contrademanda de ésta. Las memorias de Edith Farnsworth ofrecen un relato casi literario de las fases iniciales del proyecto:

Empezamos a vernos de tanto en tanto y a hacer frecuentes excursiones dominicales a Plano. (...) Cuando llegó el tiempo cálido, tuvimos que abrir senderos entre la maleza y la hierba de la pradera para llegar a la ribera. (...) Desde la orilla estudiamos varios 
emplazamientos para la casa y clavamos unas cuantas estacas provisionales. "Mies, ¿qué materiales de construcción estás considerando para la casa?" "Yo no plantearía el problema de ese modo. No pensaría "Vamos a construir una casa de ladrillo o de hormigón armado". Pensaría que aquí, donde todo es hermoso y la intimidad no es un problema sería una pena levantar un muro opaco entre el exterior y el interior. Así que creo que deberíamos construir una casa de acero y vidrio; de ese modo permitiremos que el exterior entre adentro. Por otro lado, si estuviésemos construyendo en la ciudad o en la periferia, la haría opaca hacia afuera y dejaría entrar la luz por un patio jardín situado en medio (Farnsworth 2016: 303-304).

Si tenemos en cuenta que tras este pabellón de vidrio, con un núcleo central que escondía el cuarto de baño y su estrecha cocina alineada, Mies diseñó el pináculo de la construcción moderna en altura -el edificio Seagram (1954-1958), edificación vidriada con marco de bronce en la avenida Park, en Nueva York-, entendemos porqué a partir de entonces las grandes urbes del planeta levantaron prismas miessianos replicantes hasta la extenuación de la mirada. Entendemos cómo los edificios de vidrio y acero definieron el paisaje urbano a finales del siglo XX. Entendemos porqué Mies se distingue por sus cajas prismáticas, su impresionada abstracción, una pureza estructural, uniones ocultas, simplicidad de manifiestos minimalistas y la utilización de materiales nobles de manera estratégica.

Es más difícil, sin embargo entender, cómo el espacio desfigurado de la abstracción y la transparencia terminan enfrentándonos a la violencia del proyecto heroico. Es difícil entender cómo la falta de velos, nos introduce en la sociedad de la transparencia de Rosseau como un órgano censor del control y la vigilancia totales. El hombre es, según Ernst Bloch, "per se impsum, un ser reflectante y anticipador" (Bloch 2017: 81). Por tanto, aunque esté programado para la acción social, ésta puede comprender la acción pasiva o aquiescente. Todo orden racional tiene una racionalidad propia, en suma, difícilmente puede ser programado como base de entendimiento colectivo, es decir, que un sistema formalizado puede ser independiente de los individuos. Toda utopía está en conflicto con un orden existente pero lo está en nombre de una idea, o sea, que el conflicto nace en la entelequia de visualizar alternativas. Toda acción rizomática, extensiva, invadiente, por más que nazca de valores "ideales", se vuelve autoritaria y totalizante. Theodore Dreiser, escribía en 1923 sobre Nueva York: "E1 gran Mundo sigue su curso. Nuestra parcela no es ésta ya que no somos los que aguardan en la oscuridad" (Dreiser 2018: 335). Finalmente, somos producto de una rendición por persuasión. También por proyección que es la forma en que lo evidente se convierte en catalizador de lo ordinario. Porque en el deseo de elevación también está el encuentro con el órgano que proyecte ese sueño constructivo o habitacional. Para Byung-Chul Han, "exposición es explotación. El imperativo de la exposición aniquila el habitar mismo. Si el mundo se convierte en un espacio de exposición, el habitar no es posible (Han 2013: 30).

Para Heidegger el habitar es construir, pero, en cierto modo, determina que sólo podemos habitar bajo la extorsión del desarraigo. Somos, finalmente, sujetos desarraigados habituados a habitar en lo que los estoicos definían como oikesis, estar siempre en tránsito hacia el hogar, o permanecer en él. Pero en suma, establecidos siempre en una superstición de fijeza que por el contrario nos devuelve la incertidumbre. Ya no habitamos ciudades sino territorios, según Massimo Cacciari, por tanto, somos hijos 
de una Exopolis expuestos a fuerzas exógenas y al crecimiento exterior de nuestras ciudades (Soja 2008: 355).

La membrana transparente conformada por las reglas técnicas de la eficiencia debe ir acompañada por la conservación identitaria de un grupo a través del tiempo. Pero dicha conservación parece seriamente bloqueada. Hay un paréntesis de conformación política que debiera vincular el pasado con un anticipo del futuro. Cualquier órgano de poder debiera ser un arbitraje entre las aspiraciones de diferentes generaciones. La cuestión técnica, sin embargo, sólo opera en el presente por más que se asocie a la precedencia. Pero los símbolos de los requisitos e imperativos que quedan reprimidos dentro de la sociedad del presente se manifiestan como patologías de incomunicación. Deformaciones de un sistema que crece asentado en la anomalía. De este modo, la transparencia carece de trascendencia porque se desarrolla desde la ilusión y la apariencia. "La sociedad de la transparencia es sociedad de la información. En este sentido, la información es, como tal, un fenómeno de la transparencia, porque le falta toda negatividad. Es un lenguaje positivizado operacionalizado" (Byung-Chul Han, 2013: 77).

La Ventana de Overton es una teoría política que detalla con puntual rigor y precisión el modo en que se puede modificar la percepción de la opinión pública para que las ideas que antes se consideraban insensatas e imprudentes sean aceptadas a lo largo del tiempo. De tal forma, que ninguna prohibición, perversión o aberración escapen a la eficacia de esta técnica. En definitiva, y a través de diferentes pasos, se podría franquear desde lo impensable y radical a lo popular y político. Cambiar, en suma, de modo drástico y extremado la valoración del individuo. Es sorprendente cómo la ventana que es sinónimo de luz y transparencia ha ido conformándose alegóricamente y operacionalmente como teoría política, sistema operativo de ordenador o pantallización total. Este es el mundo heredado de cristal, como diría Ballard:

De la misma manera que una solución supersaturada se descarga en una masa cristalina, la supersaturación de materia en nuestro continuum lleva a la aparición de masas cristalinas en una matriz espacial paralela (Ballard 1991: 92).

\section{Bibliografía citada}

Ballard, J. G. 1991. El mundo de cristal. Buenos Aires: Minotauro.

Bloch, Ernst. 2017. Despedida de la utopía. Madrid: A. Machado Libros.

Dreiser, Theodore. 2018. Nueva York. El color de una gran ciudad. Madrid: Abada Editores SL. Farnsworth, Edith. 2016. Ludwig Mies van der Rohe. Barcelona: Reverté.

González Martínez, Plácido. 2015. A la luz de Hilberseimer. Sevilla: Vibok Works.

Gropius, Walter. 1966. La nueva arquitectura y la bauhaus. Barcelona: Lumen. , 1959. Alcances de la arquitectura integral. Buenos Aires: Ediciones La isla.

Han, Byung-Chul. 2013. La sociedad de la transparencia. Barcelona: Herder.

Lefebvre, Henri. 2013. La producción del espacio. Madrid: Capitán Swing Libros SL.

Lynch, Kevin. 2005. Echar a perder. Un análisis del deterioro. Barcelona: Gustavo Gili.

Scheerbart, Paul. 1998. La arquitectura de cristal. Murcia: Colegio oficial de aparejadores

y arquitectos técnicos de Murcia.

Sloterdijk, Peter. 2003. Esferas I. Madrid: Siruela.

Soja, Edward W. 2008. Posmetrópolis, Madrid: Traficantes de sueños.

Taut, Bruno. 1997. Escritos expresionistas. Madrid: El Croquis Editorial. 


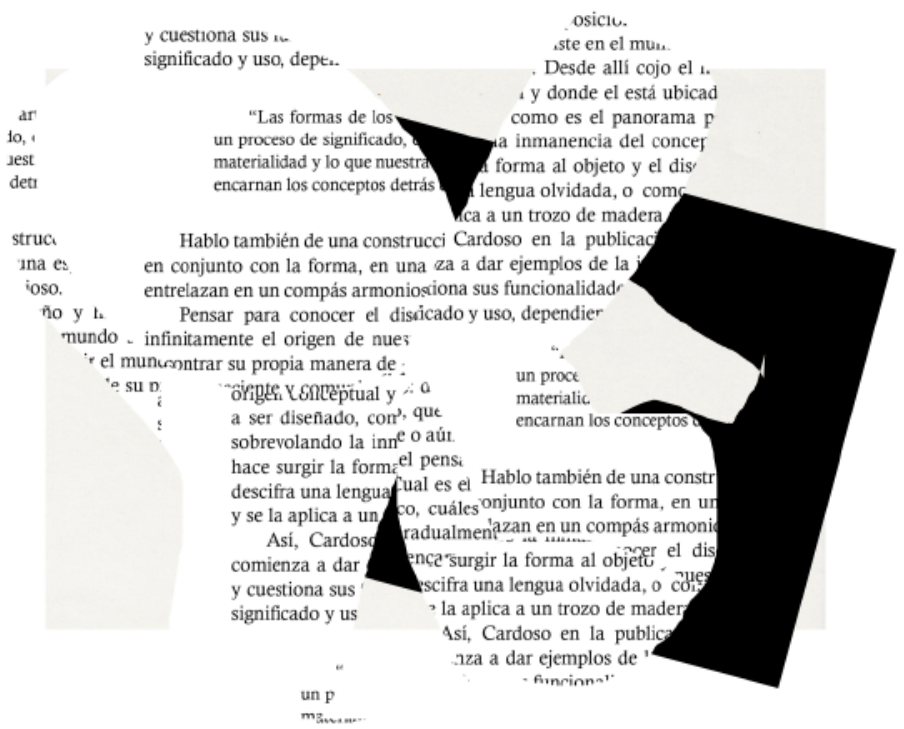

"Lo impreso exige una humildad de espíritu por cuya falta muchas de las bellas artes se tambalean ahora en experimentos de autoconciencia y sensiblería. No hay nada simple ni aburrido en lograr una página transparente. La ostentación vulgar es el doble de fácil que la disciplina".

Beatrice Warde, The Crystal Goblet, or why printings should be invisible (1930)

"El diseño que es objetivo, comprometido con el bien común, bien compuesto y delicado, constituye la base del comportamiento democrático".

Josef Müller-Brockmann, Grid and Design Philosophy (1981) 

EDITA

\section{SEyTA.}

SOCIEDAD ESPAÑLAA
DE ESTETICA Y TEORIA DE LAS ARTES

CON LA COLABORACIÓN DE

\begin{tabular}{|c|c|c|}
\hline 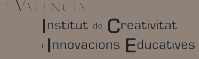 & $\begin{array}{l}\text { VNIVIRSIIN } \\
\text { II) VIIINCL Departament de Filosofia }\end{array}$ & 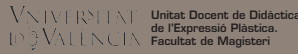 \\
\hline $\begin{array}{l}\text { ESTETICA } \\
\text { FLOSOFIA }\end{array}$ & 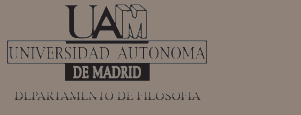 & $\begin{array}{l}\text { UAB } \\
\begin{array}{l}\text { Universitat Autònoma } \\
\text { de Barcelona }\end{array}\end{array}$ \\
\hline
\end{tabular}

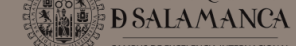

https://ojs.uv.es/index.php/LAOCOONTE/index 